\title{
THE EFFICIENCY OF UNDERGRADUATE ACCOUNTING EDUCATION: A RESEARCH ON SWORN-IN CPAS
}

\author{
DOI: 10.17261/Pressacademia.2019.1147 \\ PAP-IFC- V.10-2019(15)-p.75-79
}

\section{Huseyin Mert}

Istanbul Okan University, Faculty of Business and Administrative Sciences, Department of Accounting and Auditing, Istanbul, Turkey huseyin.mert@okan.edu.tr, ORCID ID: 0000-0001-5391-7865.

To cite this document

Mert H., (2019). The efficiency of undergraduate accounting education: a research on sworn-in CPAs. PressAcademia Procedia (PAP), V.10, p.75-79

Permemant link to this document: http://doi.org/10.17261/Pressacademia.2019.1147

Copyright: Published by PressAcademia and limited licenced re-use rights only.

\section{ABSTRACT}

Purpose- In the adequacy of education' quality; program curriculum, structure and number of faculty members are important. In this study, it is tried to examine the adequacy of accounting education given at undergraduate level.

Methodology- Sworn-in Certified Public Accountancy has been regulated as the top title in our country's accounting professional law. A research has been made on Sworn-in Certified Public Accountants and their opinions have been tried to be revealed. Survey method was used in the research and the results were tested using statistical methods and the results were explained.

Findings- The demographic characteristics of the sworn-in Certified Public Accountants were determined. Based on these characteristics, the sample was grouped and their opinions regarding the adequacy of accounting education and their development towards education were determined.

Conclusion- With this research, it is seen that sworn-in Certified Public Accountants do not find accounting education successful enough at undergraduate level.

Keywords: Undergraduate education, accounting education, success in education ve quality, accounting and audit professions. JEL Codes: M40, M41, M42.

\section{LISANS DÜZEYINDE MUHASEBE EĞitiMININ YETERLiLiĞiNE YÖNELIK YEMINLi MALi MüŞAVIRLER ÜZERINDE BIR ARAŞTIRMA}

\section{ÖZET}

Amaç- Eğitimin kalite olarak yeterliliğinde; program müfredat yapısı, öğretim elemanlarııı yapısı ve sayısı gibi unsurlar önemlidir. Bu çalışmayla lisans düzeyinde verilen muhasebe eğitiminin yeterliliği incelenmeye çalışııııı̧tır.

Yöntem- Ülkemiz muhasebe meslek hukukunda, Yeminli Mali Müşavirlik üst unvan olarak düzenlenmiştir. Konuyla ilgili, Yeminli Mali Müşavirler üzerinde bir araştırma yapılarak görüşleri ortaya çıkartılmaya çalışıııı̧̧ır. Araştırmada anket yöntemi kullanılmış ve sonuçlar istatistik yöntemler kullanılarak test edilmiş ve elde edilen sonuçlar açıklanmıştır.

Bulgular- Örneklemi oluşturan yeminli mali müşavirlerin demografik özellikleri tespit edilmiştir. Örneklem bu özelliklerden hareketle gruplandırımış ve gruplar itibari ile muhasebe eğitiminin yeterliliğine ilişkin ve eğitimin geliştirilmesine yönelik görüşleri tespit edilmiştir. Sonuç- Bu araştırma ile yeminli mali müşavirlerin lisans düzeyinde muhasebe eğitimini yeterince başarılı bulmadıkları görülmüştür.

Anahtar Kelimeler: Lisans eğitimi, muhasebe eğitimi, eğitimde başarı ve kalite, muhasebe ve denetim mesleği JEL Kodları: M40 , M41, M42.

\section{GiRiş}

Küreselleşmeyle birlikte işletmelerin yaşamış olduğu temel sorun rekabettir. Bu sorun karşısında işletmelerin başarılı olabilmesi için güçlü yönetim yapılarına sahip olmaları ve kaynaklarını etkin kullanmaları son derece önemlidir. İşletmelerin bu yönde alacakları kararlara temel oluşturacak muhasebe bilgilerinin güvenilir olması ve işletme yönetimlerine zamanında raporlanması gerekmektedir.

Lisans düzeyinde muhasebe eğitiminin amacı işletmelerin bu yönde ihtiyaç duydukları nitelikli işgücü ve yönetici kadroların yetiştirilmesidir. Bu doğrultuda verilen eğitimin yeterliliği açısından; müfredat yapısı, öğretim elemanlarının niteliği ve teknolojik alt yapı önemlidir.

Araştırmanın amacı lisans düzeyinde verilen muhasebe eğitiminin yeterliliğinin yeminli mali müşavirler üzerinde araştırılmasıdır. Daha önce eğitimin yeterliliğinin, öğrenciler ve sayıştay denetçileri üzerinde araştırılması yönünde çalışmalar yapılmıştır. Ancak yeminli mali müşavirler üzerinde araştırılması yönünde bir çalışmaya rastlanmamıştır. Bundan hareketle lisans düzeyinde verilen muhasebe eğitiminin yeterliliğinin yeminli mali müşavirler üzerinde araştırılması konu olarak seçilmiştir. 
Yeminli mali müşavirlik; muhasebe meslek hukukuna göre mesleğin üst ünvanıdır. Meslek kanunu 9. ncu maddesinde yeminli mali müşavir olabilmenin özel şartları açıklanmıştır. Buna göre yeminli mali müşavir olabilmek için;

a- $\quad$ En az 10 yıl serbest muhasebeci mali müşavirlik yapmış olmak,

b- Yeminli mali müşavirlik sınavını vermiş olmak,

c- Yeminli mali müşavirlik ruhsatını almış olmak, şartları aranır.

Yeminli mali müşavirlik ve serbest muhasebeci mali müşavirlik sınav yönetmeliğinin 14. ncü maddesine göre yeminli mali müşavirlik sınav konuları şunlardır;

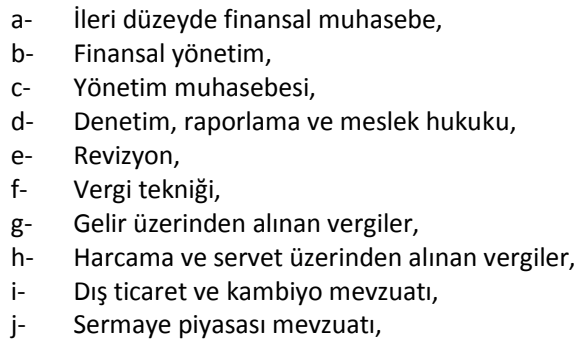

Sınav yönetmeliğinin 16. ncı maddesine göre sınavda başarılı sayılmak için sınav konularının her birinden 100 üzerinden en az 50 alınması şartıyla, alınan notların aritmetik ortalamasının en az 65 olması gerekir.

Görüldüğü üzere yeminli mali müşavirlik üst unvan olmakla birlikte, yemini mali müşavir olmak için zorlu bir süreci tamamlamak gerekir. Yeminli mali müşavirler, aynı zamanda genellikle lisans düzeyinde muhasebe eğitimi almış olanları; çalıştıranlar ve işe alanlardır. Bu nedenle, hem mesleğin yetkin unsuru ama aynı zamanda lisans düzeyinde eğitim almış olanları özellikleri itibariyle en iyi tanıyan kişi olarak, bu araştırmanın yeminli mali müşavirler üzerinde yapılması tercih edilmiştir.

Bu çalışmada; Türkiye'deki yükseköğretim kurumlarında lisans düzeyinde verilen muhasebe eğitiminin yeterliliğine ilişkin bir araştırma yapılmıştır. Çalışmada; lisans düzeyinde muhasebe eğitiminin önemine ilişkin bilgiler verilmiştir. Ayrıca konuya ilişkin literatür taraması yapılmış ve yapılan araştırmanın sonucunda; Türkiye'deki yükseköğretim kurumlarında lisans düzeyinde verilen muhasebe eğitiminin önemi değerlendirilmiştir ve bu bağlamda eksikliklerin tamamlanmasına yönelik öneriler geliştirilmiştir.

\section{LITERATÜR INCELEMESI}

Konuyla ilgili kapsamlı literatür taraması yapılmıştır. Bu doğrultuda tespit edilen çalışmalara kapsam ve sonuçları yönünden aşağıda yer verilmiştir:

"Lisans Düzeyindeki Muhasebe Eğitiminin Etkinliği: Sayıştay Özelinde Ampirik Bir Çalışma” konulu bu makalede; ülkemizde muhasebe eğitiminin etkinliği ve yeterliliği incelenmiştir. Araştırmayla, sayıştay denetçilerinin konuya ilişkin görüşleri ortaya çıkartılmaya çalışımıştır. Bu çalışmayla, muhasebe eğitiminde etkinliğin arttırılması ve sayıştay'ın ihtiyaçlarını karşılamaya yönelik ders ve içeriklerinin, üniversite-kurum işbirliğiyle belirlenmesi gerektiği sonucuna ulaşılmıştır (Ünal ve Doğanay, 2009, s.134-135).

"Muhasebe Eğitiminde Teknoloji Kullanılmasına Öğrencilerin Bakışı: Kafkas Üniversitesinde Bir Araştırma" konulu bu makalede; muhasebe eğitiminin genel amacı, faydalı olabilecek gerekli muhasebe bilgisinin verilmesi ve eğitim sırasında gerekli materyallerin kullanımının öğretilmesi olarak, tespit edilmiştir. Bu çalışmayla, öğrencilerin teknolojiye bakış açıları ve teknolojik ürünler kullanmanın muhasebe derslerine olan etkileri öğrenci bakışıyla değerlendirilmeye çalışılmıştır. Çalışmanın sonucunda, eğitim sürecinde sadece bilginin öğretilmesinin gelecek için büyük eksiklik oluşturacağı tespitine ulaşılmıştır (Öztürk ve Kutlu, 2017, s. 796-797).

“Muhasebe Dersi Alan Öğrencilerin Muhasebe Dersine Yönelik Algıları ve Muhasebe Öğretim Elemanlarından Beklentileri Üzerine Mehmet Akif Ersoy Üniversitesinde Bir Araştırma” konulu makalede; muhasebe dersi alan farklı bölümlerdeki öğrencilerin, dersin verilme şekli ve öğretim elemanlarının özellikleriyle ilgili düşünceleri tespit edilmeye çalışılmıştır. Bu çalışmayla öğrencilerin; özellikle teknolojiyi kullanabilen, öğrencileriyle iyi iletişim kurabilen, öğretmeyi pekiştiren ve özellikle mesleki etik becerisine sahip, öğretim elemanlarını istedikleri sonucuna ulaşılmıştır (Tuğay, 2014, s.64-65).

"Five ideas designed to rile everyone who cares about accounting education", konulu makalede ise; üniversite düzeyinde muhasebe eğitiminin tasarımını ve sunumunu geliştirmek için beş tane fikir öne sürülmüştür. Bu nitel çalışmada öne sürülen fikirler, muhasebe eğitimcilerinin öğretme ve öğrenme ortamını nasıl geliştirebileceğini ve böylelikle etkin öğrenme sürecinin nasıl gerçekleşeceğini tartışmıştır (Adler, 1999, s. 246-247).

Ayrıca başka bir çalışmada mezun olan öğrencilerin kariyerleri için önemli olduğunu düşündükleri becerilere ve niteliklere ilişkin algılarını ve bu becerilerin lisans programları süresince geliştirilmesine verilen önem incelenmiştir. Çalışma ayrıca, farklı bir işveren grubu tarafından beklenen becerileri ve nitelikleri inceleyerek ve öğrenci algıları ile işveren beklentileri arasındaki boşlukları da incelemiştir. Bu çalışmanın sonucunda öğrencilerin beklentileri ve işverenlerin ihtiyaçları göz önüne alındığında, muhasebe mezunları bugünün küresel iş ortamında hayatta kalabilmek için muhasebe programlarında kazandırılan becerilere ve iş hayatına yönelik niteliklere özellikle önem verilmesi gerekliliği ortaya çıkmıştır. (Kavanagh and Drennan, 2008, s.3;18)

Görüldüğü üzere faydalanılan çalışmaların çoğunluğu, muhasebe eğitiminin kapsamı ve nasıl olması gerektiğine yöneliktir. Bu eğitimin yeterliliğine yönelik öğrenciler ve sayıştay denetçileri üzerinde araştırma amaçlı çalışmalar da görülmektedir. Ancak ülkemiz meslek hukukuna göre üst mesleki unvan olarak belirlenmiş olan Yeminli Mali Müşavirler nezdinde yapılmış bir çalışmaya rastlanmamıştır. Bu yönüyle çalışmamız alanında özgün özelliği taşımaktadır. 


\section{ARAŞTIRMA}

\subsection{Araştırmanın Amacı}

Bu araştırma; "lisans düzeyinde muhasebe eğitiminin yeterliliğini”, yeminli mali müşavirler üzerinde yapılan çalışmayla ortaya çıkarmayı amaçlamaktadır. Çalışmayla aşağıdaki sorulara cevap aranmıştır:

1- Yeminli Mali Müşavirlerin bakışıyla, lisans düzeyinde muhasebe eğitiminin eksiklikleri nelerdir?

2- Yeminli Mali Müşavirlerin, lisans düzeyinde muhasebe eğitiminin başarılı olmasına yönelik beklentileri nelerdir?

Bu doğrultuda; lisans düzeyinde muhasebe eğitiminin, eksiklikleri tespit edilerek bunların giderilmesine yönelik neler yapılması gerektiği konusunda öneriler geliştirilmeye çalışılmıştır.

\subsection{Araştırmanın Yöntemi ve Verilerin Toplanması}

Yeminli Mali Müşavirler bakışıyla, 'lisans düzeyinde muhasebe eğitiminin yeterliliğini' ölçmeyi hedefleyen bu çalışmada nitel araştırma yöntemi kullanılmıştır. Anket yoluyla, konuyla ilgili sorulan sorularla yeminli mali müşavirlerin görüşleri tespit edilmeye çalışılmıştır.

Bu doğrultuda 198 yeminli mali müşavire anket ulaştırılmış olup, bunlardan 162 sinden geri dönüş alınabilmiştir.

Örneklem içerisinde yer alan yeminli mali müşavirlerden 131 kişi $(\% 80,9)$ mesleği 10 yıldan fazla icra etmekte olup, en büyük grubu oluşturmaktadır.

Örneklem içinde yer alan yeminli mali müşavirlerin 153'ü $(\% 94,4)$ mesleğini bağımsız olarak icra ederken, 9 kişi $(\% 5,6)$ bağımlı olarak çalışmaktadırlar.

\subsection{Araştırmanın Bulguları}

\subsubsection{Demografik Bilgiler}

\begin{tabular}{|c|c|c|}
\hline Meslekteki Hizmet Süresi & Kişi Sayısı & Oranı \\
\hline 5 yıldan az & 20 & $12,3 \%$ \\
\hline 5-10 yıl arası & 11 & $6,8 \%$ \\
\hline 10 yıldan fazla & 131 & $80,9 \%$ \\
\hline Toplam & 162 & $100,0 \%$ \\
\hline
\end{tabular}

Hizmet süreleri 10 yıldan fazla olanlar 131 kişi $(\%$ 80,9) ile en büyük grubu oluştururken, onu hizmet süreleri beş yıldan az olanlar takip etmektedir. Bu grupta 20 kişi olup örneklem içindeki oranı \% 12,3 tür..

\begin{tabular}{|l|c|c|}
\hline \multicolumn{1}{|c|}{ Çalışma Şekli } & Kişi Sayısı & Oranı \\
\hline Bağımlı & 9 & $5,6 \%$ \\
\hline Bağımsız & 153 & $94,4 \%$ \\
\hline Toplam & 162 & $\mathbf{1 0 0 , 0 \%}$ \\
\hline
\end{tabular}

Örneklem içerisinde yer alan yeminli mali müşavirlerden 153 (\% 94,4) kişi bağımsız olarak mesleklerini uygularken, 9 kişi $(\% 5,6)$ bağımlı olarak çalışmaktadır.

\subsubsection{Muhasebe Eğitimine Yönelik Tespitler}

\begin{tabular}{|l|c|r|}
\hline $\begin{array}{c}\text { Lisans düzeyinde verilen muhasebe eğitiminin aşağıda belirtilen } \\
\text { hangi konularda yeterli olduğunu düşünüyorsunuz? }\end{array}$ & Kişi Sayısı & Oranı \\
\hline Temel Muhasebe İşlemleri & 134 & $82,7 \%$ \\
\hline Muhasebe Organizasyonu ve İş Akışı & 45 & $27,8 \%$ \\
\hline Tek Düzen Hesap Planı & 87 & $53,7 \%$ \\
\hline Dönem Sonu İşlemler & 76 & $46,9 \%$ \\
\hline Mali Tablolar & 71 & $43,8 \%$ \\
\hline Meslek ve Vergi Mevzuatı & 53 & $32,7 \%$ \\
\hline Muhasebe Standartları & 42 & $25,9 \%$ \\
\hline Denetim Standartları & 30 & $18,5 \%$ \\
\hline Finans Sektörü Bilgisi & 16 & $9,9 \%$ \\
\hline
\end{tabular}

Temel muhasebe işlemleri yönünden eğitimin yeterli olduğunu düşünenler 134 kişi olup (\%82,7) en büyük grubu oluşturmaktadır. Eğitimin, tek düzen hesap planı yönünden yeterli olduğunu düşünenler 87 kişi olup $(\% 53,7)$ ikinci grubu oluşturmaktadırlar. Eğitimin; dönem sonu işlemleri yönünden yeterli olduğunu düşünenler 76 kişi $(\% 46,9)$ olup üçüncü grubu oluşturmaktadırlar 


\begin{tabular}{|c|c|c|}
\hline $\begin{array}{l}\text { Lisans düzeyinde verilen muhasebe eğitiminin mesleki açıdan } \\
\text { yeterli olduğunu düşünüyor musunuz? }\end{array}$ & Kişi Sayısı & Oranı \\
\hline Kesinlikle Yetersiz & 37 & $23,1 \%$ \\
\hline Yetersiz & 30 & $18,8 \%$ \\
\hline Kararsızım & 65 & $40,6 \%$ \\
\hline Yeterli & 24 & $15,0 \%$ \\
\hline Kesinlikle Yeterli & 4 & $2,5 \%$ \\
\hline Boş & 2 & $1,3 \%$ \\
\hline Toplam & 162 & $\% 100$ \\
\hline
\end{tabular}

Örneklem içerisinde muhasebe eğitiminin mesleki açıdan yeterli olduğunu düşünenler 28 (\% 17,5) iken, yeterli olmadığını düşünenler 67 (\% 41,9) kişidir. Görüldüğü üzere örneklem içinde çoğunluk eğitimin mesleki açıdan yeterli olmadığını düşünmektedir.

\begin{tabular}{|l|c|l|}
\hline $\begin{array}{c}\text { Muhasebe eğitiminin iş hayatında başarıya yönelik olması için } \\
\text { aşağıdaki uygulamalardan hangileri yapılmalıdır? }\end{array}$ & Kişi Sayısı & Oranı \\
\hline Staj & 109 & $67,3 \%$ \\
\hline COOP (İşyerinde Eğitim Programı) & 110 & $67,9 \%$ \\
\hline Markalı Dersler & 29 & $17,9 \%$ \\
\hline
\end{tabular}

Muhasebe eğitiminin iş yaşamına yönelik uygulamalı olması yönünden 110 kişi $(\% 67,9)$ COOP uygulamasını önerirken, 109 kişi (\%67,3) staj uygulamasını yöntem olarak önermektedir. Görüldüğü üzere örneklem içinde yer alan yeminli mali müşavirlerin ağırlıklı bir bölümü iş yerinde eğitim programını yöntem olarak önermektedir.

\subsubsection{Muhasebe Eğitiminin Başarısı için Yapılması Gerekenlerin Tespiti}

Örneklem içerisinde 107 kişi (\%66) lisans düzeyinde verilen muhasebe eğitimini, 'uygulamalı olmadığı yönünden eksik bulmaktadır. Örneklem içerisinde 39 kişi $(\% 24,1)$ lisans düzeyinde verilen muhasebe eğitimini, 'gelişen teknolojiyi ve programları kullanabilme' yönünden eksik bulmaktadır. Örneklem içerisinde 45 kişi $(\% 27,8)$ lisans düzeyinde verilen muhasebe eğitimin, 'mesleki bilgilere hakim olma' yönünden eksik bulmaktadır.

\begin{tabular}{|l|l|l|}
\hline $\begin{array}{c}\text { Lisans düzeyinde eğitim almış muhasebe elemanının çalışma } \\
\text { hayatında daha başarılı olabilmesi ççin, üniversite eğitiminde eksik } \\
\text { kalan konular nelerdir? }\end{array}$ & Kişi Sayısı & \multicolumn{1}{c|}{ Oranı } \\
\hline Eğitimin Uygulamalar Ağırlıklı Olması & 107 & $66,0 \%$ \\
\hline Gelişen Teknolojiyi ve Programları Kullanabilmeli & 39 & $24,1 \%$ \\
\hline Mesleki Bilgilere Hakim Olmalı & 45 & $27,8 \%$ \\
\hline En az 1 yarıyıl iş yerinde uygulamalı staj görmeli & 27 & $16,7 \%$ \\
\hline Mevzuata Hakim Olmalı & 37 & $22,8 \%$ \\
\hline Yabancı Dili Olmalı & 1 & $0,6 \%$ \\
\hline Sorumluluk Bilincine Sahip Olmalı & 12 & $7,4 \%$ \\
\hline Görev Üstlenmeye ve Ekip Çalışmasına Yatkın Olmalı & 16 & $9,9 \%$ \\
\hline
\end{tabular}

\section{SONUÇ}

Bu çalışmanın amacı; "Yeminli Mali Müşavirler bakışıla, lisans düzeyinde muhasebe eğitiminin yeterliliğinin araştırıması” olarak belirlenmiştir. Bu doğrultuda, Yeminli Mali Müşavirler üzerinde araştırma yapılmıştır. Araştırmanın sonuçları aşağıda özetlenmiştir:

- Yeminli Mali Müşavirlerin çoğunluğu lisans düzeyinde muhasebe eğitimini; 1- Temel muhasebe işlemleri, 2-Tek düzen hesap planı, 3- Dönem sonu muhasebe işlemleri, 4- Mali Tablolar, konularında yeterli bulmaktadır. Ancak yine çoğunluk eğitimi; 1- Meslek ve vergi mevzuatı, 2- Muhasebe organizasyonu ve iş akışı, 3- Muhasebe standartları, 4- Denetim standartları, 5- Finansal Yönetim, konularında yeterli bulmamaktadır.

- Yeminli Mali Müşavirlerin çoğunluğu lisans düzeyinde muhasebe eğitimini, mesleğe hazırlama yönünden yeterli bulmamaktadır.

- Yeminli Mali Müşavirler; lisans düzeyinde muhasebe eğitiminin katılımcıları iş yaşamına hazırlama yönünden; eğitim sürecinde staj uygulamasının zorunlu ve etkin hale getirilmesi ve işyerinde eğitim programlarının uygulanmasını, önermektedirler. 
- Yeminli Mali Müşavirlerin çoğunluğu lisans düzeyinde muhasebe eğitimi alanlarda; 1- Gelişen teknolojileri kullanabilme, 2- Meslek etiğini öğrenmiş olma, 3- Ekip çalışmasına uyumlu olma, 4- Sorumluluk almaya yatkın olma, özelliklerinin bulunması gerektiğini belirtmişlerdir.

- Yeminli Mali Müşavirlerin çoğunluğu lisans düzeyinde muhasebe eğitiminin başarılı olması için eğitimin uygulamalar ağırlıklı yapılması gerektiğini önermişlerdir.

Bu tespitlere dayalı olarak; Yeminli Mali Müşavirlerin, "lisans düzeyinde muhasebe eğitimini” yeterince başarılı bulmadıkları sonucuna ulaşılmıştır.

\section{KAYNAKÇA}

Adler R. W., 1999, "Five Ideas Designed to Rile Everyone Who Cares About Accounting Education", Accounting Education: An International Journal, ss. 241-247.

Kavanagh Marie H. and Drennan L., 2008, "What Skills and Attributes Does an Accounting Graduate Need? Evidence from Student Perceptions and Employer Expectations", Accounting and Finance, ss. 79 - 300.

Öztürk S. ve Kutlu H.A., 2017, "Muhasebe Eğitiminde Teknoloji Kullanılmasına Öğrencilerin Bakışı: Kafkas Üniversitesi'nde Bir Araştırma”, Muhasebe Bilim Dünyası Dergisi, ss. 781-799.

Serbest Muhasebeci Mali Müşavirlik ve Yeminli Mali Müşavirlik Kanunu (13.06.1989 Tarih ve 20194 Sayılı Resmi Gazete)

Tuğay O., 2014, "Muhasebe Dersi Alan Öğrencilerin Muhasebe Dersine Yönelik Algıları ve Muhasebe Öğretim Elemanlarından Beklentileri Üzerine Mehmet Akif Ersoy Üniversitesinde Bir Araştırma”, Eskişehir Osmangazi Üniversitesi iiBF Dergisi, Aralık 2014, ss.49-68.

Ünal O. ve Doğanay M., 2009, "Lisans Düzeyindeki Muhasebe Eğitiminin Etkinliği: Sayıştay Özelinde Ampirik Bir Çalışma", Sayıştay Dergisi, Sayı:74-75, Temmuz - Aralık 2009, ss. 117-138.

Yeminli Mali Müşavirlik ve Serbest Muhasebeci Mali Müşavirlik Sınav Yönetmeliği (16.01.2005 Tarih ve 25702 Sayılı Resmi Gazete) 